\title{
EGFR-targeted photodynamic therapy by
} curcumin-encapsulated chitosan/TPP nanoparticles

This article was published in the following Dove Press journal: International Journal of Nanomedicine

\author{
Wen-Hsuan Tsai' \\ Kun-Hua Yu' \\ Yi-Cheng Huang ${ }^{2}$ \\ Cheng-I Lee'
}

'Department of Biomedical Sciences, National Chung Cheng University, Min-Hsiung, Chia-Yi, Taiwan, Republic of China; ${ }^{2}$ Department of Food Science, National Taiwan Ocean University, Keelung City, Taiwan, Republic of China
Correspondence: Cheng-I Lee Department of Biomedical Sciences, National Chung Cheng University, 168 University Road, Min-Hsiung, Chia-Yi 621, Taiwan, Republic of China Tel +8865272 04II ext 665II

Fax +886 5272287 I

Email biocil@ccu.edu.tw

\begin{abstract}
Background: Photodynamic therapy (PDT) is an effective therapy for cancers and is a minimally invasive therapy with low dark toxicity and limited side effects. PDT employs the combination of photosensitizers with a specific light source to produce reactive oxygen species (ROS) to damage tumor cells.
\end{abstract}

Methods: We fabricated nanoparticles encapsulating curcumin through crosslinking chitosan and tripolyphosphate (TPP). Additionally, the chitosan was conjugated to epidermal growth factor in order to target the epidermal growth factor receptor (EGFR), overexpressed on cancer cells. To investigate PDT using fabricated nanoparticles, we measured cell viabilities and ROS production in relation to EGFR-overexpressing gastric cancer cells and non-cancer gastric cells.

Results: The targeting nanoparticles displayed a superior PDT effect in the cancer cell, with a resultant approximately fourfold decrease in the $\mathrm{IC}_{50}$. The PDT mechanism of curcumin-encapsulated nanoparticles is further identified as the generation of ${ }^{1} \mathrm{O}_{2}$, the major pathway in PDT.

Conclusion: These curcumin-encapsulated chitosan/TPP nanoparticles are a promising targetedPDT against EGFR-overexpressing cancers.

Keywords: EGFR-targeting, cancer, photodynamic therapy, curcumin, chitosan

\section{Introduction}

Photodynamic therapy (PDT) is a minimally invasive therapy approved for the treatment of carcinoma. ${ }^{1}$ When photosensitizers are exposed to a specific wavelength of light, the energy transfer from the photosensitizer to the nearby $\mathrm{O}_{2}$ causes the state transition of oxygen from the triplet to the singlet state (type II PDT). Alternatively, the excited photosensitizer transfers electrons to nearby biomolecules to form free radicals (type I PDT). Free radicals in type I PDT and singlet oxygen $\left({ }^{1} \mathrm{O}_{2}\right)$ in type II PDT are reactive oxygen species (ROS) and they kill nearby cells via apoptosis or necrosis. ${ }^{2}$ Singlet oxygen has been considered the major toxic agent in PDT. PDT has been tested clinically in cancers, and was found to have limited side effects and improved tumor specificity in comparison to chemotherapy or radiotherapy. However, PDT remains underutilized clinically mainly due to some dark toxicity, poor water solubility, and low target selectivity of photosensitizer. ${ }^{3}$

Curcumin is a well-known polyphenol extracted from Curcuma longa, and has been a commonly used spice for centuries. ${ }^{4}$ Other than its usage as a spice, curcumin exhibits antioxidant, anticancer, anti-inflammatory, and anti-amyloid activities, ${ }^{5-11}$ and has been used to treat wounds, infections, and tumors through traditional medicine in China and in India. ${ }^{5}$ Curcumin has been used as a photosensitizer, ${ }^{12}$ but the application of curcumin in clinical therapies is limited due to low solubility. Fortunately, the water solubility of curcumin has been improved by fabrication of 
various types of nanoparticles ${ }^{13}$ and complexation with metal complexes. ${ }^{14}$

Chitosan is a polysaccharide produced from deacetylation of chitin, which is omnipresent in the natural environment. Chitosan-based materials have drawn much attention with respect to drug-delivery systems as a result of their desirable properties, such as biocompatibility, biodegradability, and nontoxicity. ${ }^{15}$ The amine group of chitosan gets protonated in dilute acidic solution. An intermolecular crosslinking reaction can be carried out between protonated chitosan and anionic phosphate groups, such as tripolyphosphate (TPP), ${ }^{16}$ with simultaneous crosslinking and coagulation resulting in polymer networks, ${ }^{17}$ to form chitosan/TPP nanoparticles (NP) - in the range of nanometers to micrometers ${ }^{18}$ - in aqueous solution.

While many drugs for targeted therapies have been approved by the Food and Drug Administration (FDA) in the United States, ${ }^{19}$ many studies have been undertaken to achieve more precision and potentially fewer side effects. ${ }^{20}$ Due to its critical role in the progression of cancer, the epidermal growth factor receptor (EGFR) is the most common target in anticancer therapy, including in kidney, colorectal, head and neck, pancreatic, breast, medullary thyroid, and gastric cancers.

In this work, we targeted EGFR using nanoparticles that were conjugated to the epidermal growth factor (EGF) based on the formation of an amide bond between the carboxylic group in the $\mathrm{C}$-terminus of EGF and the amine groups of chitosan. The EGF-conjugated nanoparticles recognize MKN45 cells, which are EGFR-overexpressing human gastric cancer cells. As illustrated in Figure 1, the EGFconjugated chitosan is crosslinked with TPP and curcumin, which is the photosensitizer in this study, and is then trapped in the polymer network to form curcumin-encapsulated and EGF-conjugated chitosan/TPP nanoparticles (CENP) for the PDT experiments. To examine the effect of CENP, similar nanoparticles are prepared including curcumin-encapsulated chitosan/TPP nanoparticles (CNP), and EGF-conjugated chitosan/TPP nanoparticles (ENP). To compare the targeting effect of EGF and folate, folate-conjugated nanoparticles are prepared using the same approach, including folateconjugated chitosan/TPP nanoparticles (FNP) and curcuminencapsulated folate-conjugated chitosan/TPP nanoparticles (CFNP). After PDT, the effect was evaluated by cellular assays. Herein, the advantages and the challenges of these curcumin-encapsulated chitosan/TPP nanoparticles for EGFR-targeting PDT are discussed.

\section{Materials and methods Conjugation of EGF to chitosan}

Chitosan was added to $100 \mathrm{~mL} 2 \%(\mathrm{v} / \mathrm{v})$ acetic acid to reach a concentration at $2 \%(\mathrm{w} / \mathrm{v})$, and stirred at room temperature for 24 hours. After the chitosan was completely dissolved, the $\mathrm{pH}$ of the solution was adjusted to 6 with sodium hydroxide. Subsequently, the conjugation of chitosan and EGF (with
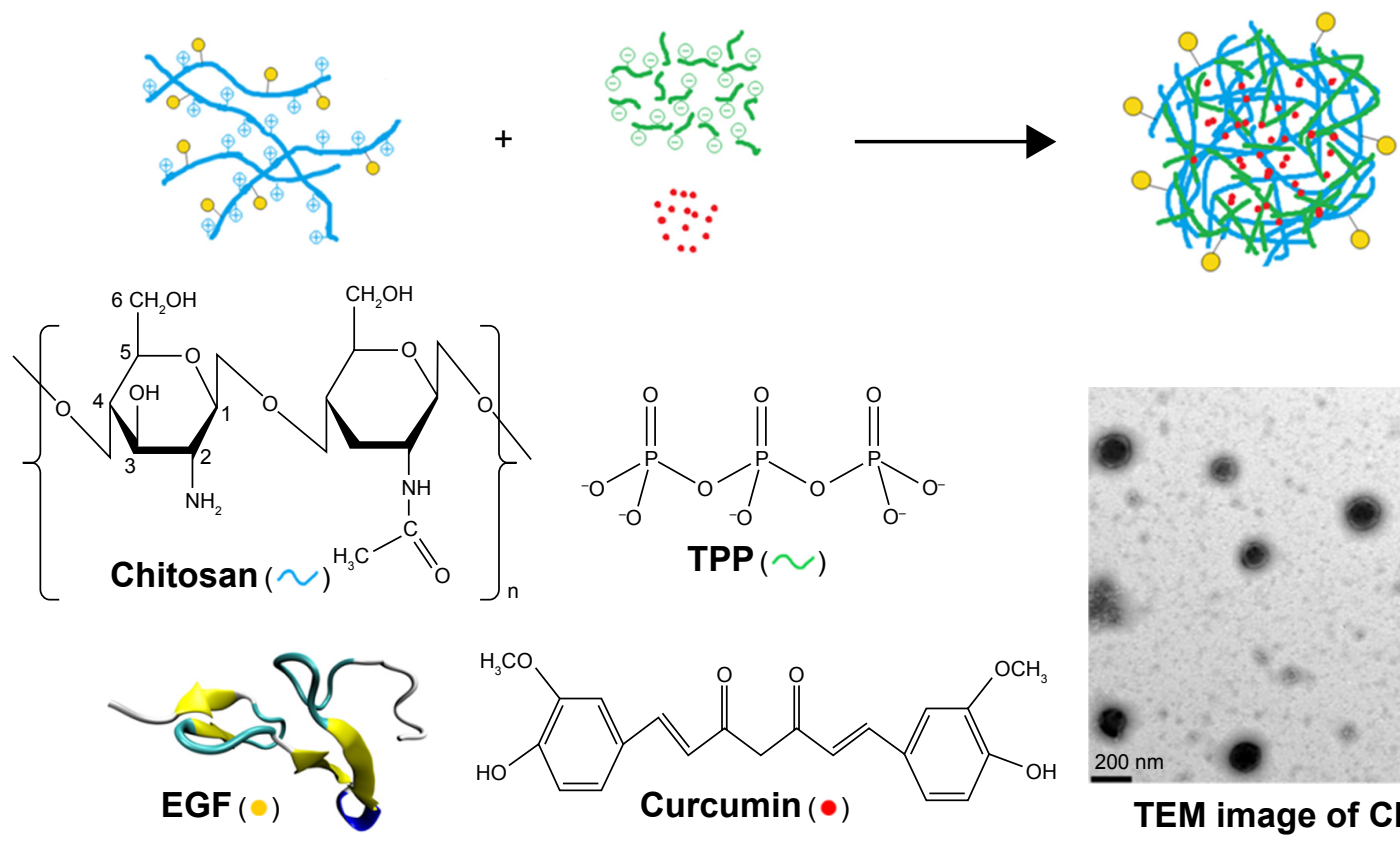<smiles>O=P([O-])([O-])OP(=O)([O-])OP(=O)([O-])O</smiles>
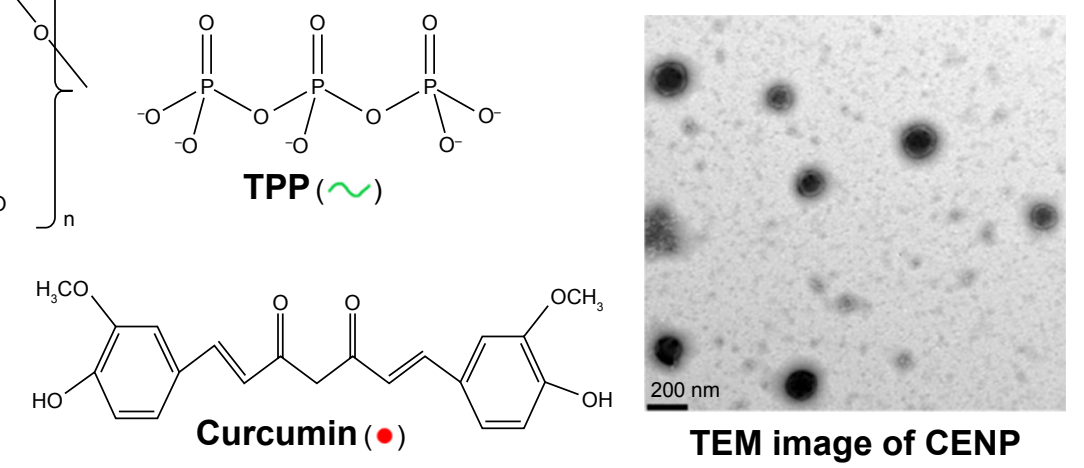

Figure I A schematic diagram for the nanoparticle assembly of CENP from EGF-conjugated chitosan, TPP, and curcumin.

Abbreviations: CENP, curcumin-encapsulated and EGF-conjugated chitosan/TPP nanoparticles; EGF, epidermal growth factor; TEM, transmission electron microscopy; TPP, tripolyphosphate. 
a molar ratio of 100:1) was achieved through chemical crosslinking using a coupling agent $\mathrm{N}$-hydroxysuccinimide (NHS; $1 \mathrm{mM}$ ) and 1-ethyl-3-(3-dimethylaminopropyl) carbodiimide hydrochloride (EDC; $1 \mathrm{mM})$. The conjugated product (EGF-chitosan) was then dialyzed against deionized water for 1 day. To estimate the conjugation rate of the EGF to chitosan, we conducted titration of EGF-conjugated chitosan with hydrochloric acid. For comparison of the targeting effect, folate was also used to prepare a folate-chitosan conjugate using the same procedure.

\section{Self-assembly of chitosan/TPP nanoparticles}

The ionic-gelation method was employed for the synthesis of NP using sodium TPP as a crosslinking agent. The mass ratio of chitosan:TPP was optimized and kept at a ratio of 5. The curcumin was pre-mixed with the same volume of $0.1 \%$ TPP (w/v) and the mixture was added dropwise into $0.5 \%$ (w/v) chitosan solution under probe-type ultrasonication. For nanoparticles with EGF-conjugation, EGF-chitosan rather than unmodified chitosan was used.

\section{Characterization of nanoparticles}

The hydrodynamic diameter $\left(\mathrm{D}_{\mathrm{h}}\right)$, polydispersity index (PDI), and zeta potential of nanoparticles were measured by dynamic light scattering (DLS; Malvern Nano-ZS90). The stability of NP was evaluated by $\mathrm{D}_{\mathrm{h}}$ and PDI at neutral $\mathrm{pH}$ as well as at $\mathrm{pH} 4$ and 8.8 .

Nanoparticles were lyophilized and the powdered sample was measured with a Fourier transform infrared (FT-IR) spectrometer equipped with a mercury cadmium telluride (MCT) detector (Bruker, VERTEX 70v). The dried samples were directly placed on potassium bromide $(\mathrm{KBr})$ to form pellets under compression. The FT-IR spectra were recorded from $4,000 \mathrm{~cm}^{-1}$ to $700 \mathrm{~cm}^{-1}$ at a resolution of $4 \mathrm{~cm}^{-1}$.

The morphology of the curcumin-encapsulated and EGFconjugated nanoparticles was investigated by transmission electron microscopy (TEM; JEOL JEM-2100). Nanoparticles were immobilized on copper grids for 5 minutes, washed with deionized water four times, and then dried at room temperature for 1 day.

\section{Determination of encapsulation efficiency of nanoparticles}

Curcumin-encapsulated nanoparticles were separated from an aqueous suspension containing curcumin by centrifugation at $9,300 \mathrm{~g}$ for 5 minutes. The supernatant was collected for measurement of free curcumin by absorbance at $430 \mathrm{~nm}$ with ultraviolet-visible (UV-Vis) spectroscopy (Scinco S-3100). The curcumin encapsulation efficiency (EE) of nanoparticles was calculated as follows: $\% \mathrm{EE}=[(\mathrm{A}-\mathrm{B}) / \mathrm{A}] \times 100$, where $\mathrm{A}$ is the total amount of curcumin, $\mathrm{B}$ is the amount of free curcumin.

\section{Determination of release efficiency from nanoparticles}

Release of curcumin from nanoparticles was measured in phosphate-buffered saline (PBS) at different time intervals. Nanoparticles were removed from free curcumin by centrifugation. The curcumin in the supernatant represents the amount of curcumin released. The released curcumin was quantified by absorbance at $430 \mathrm{~nm}$. Notably, the evaluation of encapsulation and release was done in two different solution conditions.

\section{Cell culture and cell viability}

Two cell lines were used in this study including a human gastric cancer cell line (MKN45) and human gastric epithelial mucosa (non-cancer) cell line (GES). MKN45 (RCB1001) was obtained from Riken Cell Bank (Tsukuba, Japan) and GES (CVCL_EQ22 in Cellosaurus) was a gift from Professor Michael WY Chan at National Chung Cheng University. ${ }^{21}$ This study was approved by the institutional review board of Dalin Tzu Chi Hospital. These two cell lines were cultured at $37^{\circ} \mathrm{C}$ in RPMI medium supplemented with $10 \%$ fetal bovine serum, $1.5 \mathrm{~g} / \mathrm{L}$ sodium bicarbonate, $10,000 \mathrm{U} / \mathrm{mL}$ penicillin, $10 \mathrm{mg} / \mathrm{mL}$ streptomycin, and $5 \% \mathrm{CO}_{2}$.

The viability of cultured cells was assessed by WST-1 assay. Cells were plated in 96-well plates at a concentration of $1 \times 10^{4}$ cells/well. After 24 hours, cells were washed twice with $200 \mu \mathrm{L}$ PBS and treated with curcumin and nanoparticles for 4 hours, followed by PDT experiments. After PDT experiments, the cells were rinsed with PBS twice. Afterwards, an additional $100 \mu \mathrm{L}$ of medium containing WST-1 was added and then incubated for 3 hours at $37^{\circ} \mathrm{C}$ in a $\mathrm{CO}_{2}$ incubator. The absorbance of the formazan dye was measured in an ELISA reader at $450 \mathrm{~nm}$. For statistical analysis, unpaired $t$-test was conducted. The control represented cells without any treatment.

\section{PDT experiments}

Cells were incubated in medium containing curcumin or nanoparticles. After 4-hour incubation, they were subjected to irradiation with a blue light-emitting diode (LED) array ( $460 \mathrm{~nm}, 5 \pm 0.1 \mathrm{~mW}$, measured on the surface of the samples) for 30 minutes. The overall light intensity was $9 \mathrm{~J} / \mathrm{cm}^{2}$. 


\section{Measurement of intracellular ROS generation}

Intracellular ROS generation was determined by measuring the fluorescence of 2,7-dichlorofluorescein (DCF). Cells were plated separately in 24-well plates at a concentration of $1 \times 10^{5}$ cells/well. After the PDT treatment, 2,7-dichlorodihydrofluorescein diacetate $\left(\mathrm{H}_{2} \mathrm{DCF}-\mathrm{DA}\right)$ was added to the cell medium and incubated at $37^{\circ} \mathrm{C}$ for 30 minutes. These cells were then washed twice with PBS. After washing, $50 \mu \mathrm{L}$ dimethyl sulfoxide was added to cells and the fluorescence of DCF was measured using a fluorescence spectrophotometer (Perkin Elmer, Wallac 1420; Waltham, MA, USA), with excitation at $485 \mathrm{~nm}$ and emission at $530 \mathrm{~nm}$.

\section{EPR detection of radical species}

An electron paramagnetic resonance (EPR) experiment using 5,5-dimethyl-pyrroline N-oxide (DMPO) as a spin trap was conducted to identify the radical species generated in PDT. Into a solution of $10 \mu \mathrm{M} C N P$, we added $500 \mu \mathrm{M}$ DMPO prior to the illumination. Immediately after irradiation for 30 minutes, free radicals trapped by DMPO were detected with a Bruker EMX plus conducted at the X band with $12 \mathrm{~kW}$ of power supply.

\section{Fluorescence imaging of cells}

Cells were seeded on a cover glass in a 12-well plate at a concentration of $1 \times 10^{6}$ cells/well. These cells were then treated with nanoparticles for 4 hours. After the treatment, the medium was replaced with PBS. Subsequently, the cells on a cover slip were fixed by $4 \%$ formaldehyde in PBS, and then mounted on a glass slide. These cells were observed using a fluorescence microscope (Nikon, Eclipse 80i; Tokyo, Japan). DAPI, a blue dye that fluoresces upon UV excitation, was used to localize the nuclei of these cells. Curcumin emits a greenish yellow fluorescence upon excitation with blue light.

\section{Cellular uptake of curcumin in CNP- and CENP-treated MKN45}

MKN45 cells were plated in 24-well plates at a concentration of $1 \times 10^{5}$ cells $/$ well for treatments with $5 \mu \mathrm{M}$ CNP or CENP. After incubation for 2 or 4 hours, cells were washed twice with PBS and then scraped. The scraped cells were spun down at 1,000 rpm for 5 minutes. For curcumin extraction from the treated cells, the cell pellet mixed with $200 \mu \mathrm{L}$ methanol was sonicated. The cell lysate was centrifuged at $13,000 \mathrm{rpm}$ for 10 minutes. The absorbance of curcumin was measured in an ELISA reader at $450 \mathrm{~nm}$. The concentration of curcumin was determined on the basis of the build calibration curve.

\section{Apoptosis assay}

Apoptotic cells were detected by an Annexin V-FITC apoptosis detection kit (Strong Biotech Corporation, Taipei, Taiwan). The cells were plated in 6-well plates at a concentration of $1 \times 10^{5}$ cells/well. After 24 hours, cells were washed twice with $200 \mu \mathrm{L}$ PBS, and then treated with curcumin and nanoparticles for 4 hours before PDT experiments. After PDT experiments, cells were rinsed with PBS twice, centrifuged at $9,300 \mathrm{~g}$, and then suspended in $200 \mu \mathrm{L}$ staining solution containing $4 \mu \mathrm{L}$ Annexin V-FITC and $4 \mu \mathrm{L}$ propidium iodide (PI). The stained samples were incubated in the dark for 15 minutes at room temperature before measurements on a Calibur Flow Cytometer (BD Biosciences, Franklin Lakes, NJ, USA), using $488 \mathrm{~nm}$ excitation and emission at $530-575 \mathrm{~nm}$.

\section{Measurements of IL- I 0 by ELISA}

MKN45 cells were plated in 96-well plates at a concentration of $1 \times 10^{4}$ cells/well and incubated in medium with or without CENP. After 4 hours of incubation, irradiation with a blue LED array for 30 minutes was undertaken. After irradiation, cells were incubated for 2 hours at $37^{\circ} \mathrm{C}$. Sequentially, the culture medium was collected and centrifuged at 13,000 rpm for 10 minutes. Afterwards, interleukin (IL)-10 in the supernatant was quantified by using a human IL-10 ELISA kit (BioLegend, San Diego, CA, USA).

\section{Results and discussion}

\section{Fabrication and characterization of nanoparticles}

In the synthesis of NP, the mass ratio of chitosan:TPP has been tested for the smallest size and positive charge to have good interaction with cell membranes. The $\mathrm{D}_{\mathrm{h}}$, PDI, and zeta potential were measured by DLS as listed in Table S1. In the following fabrication incorporating EGF and curcumin, the mass ratio of chitosan:TPP was kept constant at 5 . In the fabrication of EGFR-directed nanoparticles, chitosan with $62 \%$ EGF-conjugation on amine groups was used. In other words, 38\% amine groups in chitosan remained protonated and potentially can crosslink with TPP to form nanoparticles. Similarly, in the fabrication of folate-conjugated nanoparticles, chitosan with 54\% folate-conjugation on amine groups was used. The physical properties of fabricated nanoparticles for further cell experiments were measured by DLS, as listed in Table 1. All types of nanoparticles are similar in their diameters and zeta potentials. Encapsulation of curcumin does not 
Table I Physical characterization of various nanoparticles used in cell experiments

\begin{tabular}{llll}
\hline Nanoparticles & $\mathbf{D}_{\mathbf{h}}(\mathbf{n m})$ & PDI & $\begin{array}{l}\text { Zeta potential } \\
(\mathbf{m V})\end{array}$ \\
\hline NP & $231.6 \pm 3.3$ & $0.167 \pm 0.038$ & $17.3 \pm 3.5$ \\
CNP & $243.3 \pm 7.6$ & $0.265 \pm 0.049$ & $17.1 \pm 0.4$ \\
ENP & $220.2 \pm 9.8$ & $0.252 \pm 0.056$ & $16.9 \pm 0.6$ \\
CENP & $235.2 \pm 5.4$ & $0.269 \pm 0.034$ & $16.4 \pm 0.2$ \\
FNP & $241.6 \pm 4$ & $0.280 \pm 0.023$ & $15.8 \pm 1.8$ \\
CFNP & $255.9 \pm 8.1$ & $0.394 \pm 0.08$ & $16.3 \pm 1.5$ \\
\hline
\end{tabular}

Abbreviations: CENP, curcumin-encapsulated and EGF-conjugated chitosan/ TPP nanoparticles; CFNP, curcumin-encapsulated folate-conjugated chitosan/ TPP nanoparticles; CNP, curcumin-encapsulated chitosan/TPP nanoparticles; $D_{h}$, hydrodynamic diameter; ENP, EGF-conjugated chitosan/TPP nanoparticles; FNP, folate-conjugated chitosan/TPP nanoparticles; NP, chitosan/TPP nanoparticles PDI, polydispersity index; EGF, epidermal growth factor; TPP, tripolyphosphate.

affect the dimension of the nanoparticles. Values of PDI are slightly enlarged when more materials are involved; however, they belong to the same range of dispersity - broader dispersions. ${ }^{22}$ The positive zeta potentials indicate that the fabricated nanoparticles are positively charged. As shown in Figure 1, CENP is quasi-spherical. The particle size is approximately $160 \mathrm{~nm}$, measured under TEM. The TEMmeasured dimension is smaller than $\mathrm{D}_{\mathrm{h}}(235 \mathrm{~nm})$, because $\mathrm{D}_{\mathrm{h}}$ is affected by solvent and the shape of the nanoparticles.

In the preparation of curcumin-encapsulated nanoparticles, CNP, CENP and CFNP were stored in the curcumin solution. Dynamically, curcumin passed in and out of NP, but the concentration of curcumin inside nanoparticles remained constant at equilibrium. Under this condition, the encapsulation efficiency of curcumin in NP was estimated to be $82.7 \% \pm 5.6 \%$, which was very favorable. A similar strategy has been used to encapsulate tea catechins, but with an efficiency of only $24 \%-53 \% .{ }^{23}$ These encapsulated nanoparticles were highly stable at neutral $\mathrm{pH}$ as $\mathrm{D}_{\mathrm{h}}$ and PDI remain constant over a period of 2 weeks, as shown in Figure S1. The high stability of NP indicates strong crosslinking between chitosan and TPP. Due to the strength of this crosslinking, the polymer network is solid even after curcumin gets released from nanoparticles. In addition, the stability of NP was tested at $\mathrm{pH} 4$ and 8.8, as shown in Figure S2. At pH 4, the $\mathrm{D}_{\mathrm{h}}$ of NP decreased slightly to $<200 \mathrm{~nm}$ from the second day onward, and PDI increased to $>0.5$ - indicating high dispersion of nanoparticles. ${ }^{22}$ At $\mathrm{pH} 8.8$, the $\mathrm{D}_{\mathrm{h}}$ fluctuated from 300 to $4,200 \mathrm{~nm}$, and PDI also increased up to 0.9, indicating severe aggregation. This instability of the polymer network could be due to reformation of ionic crosslinking caused by extra charges from the buffer. Exposure of CNP to aqueous solution causes slow release of curcumin. As shown in Figure S3, 99.75\% of the curcumin was released within 4 hours. This high efficiency of encapsulation and release of curcumin indicates that our fabricated NP is a very good drug-delivery system. However, the application of NP in PDT is limited, especially in targeted PDT.

\section{Spectroscopic characterization of nanoparticles}

The assembly of nanoparticles and conjugation of EGF are confirmed by FT-IR for the unique vibrational features of the functional groups. The FT-IR spectrum of chitosan reveals stretches of $\mathrm{O}-\mathrm{H}$ at $3,200-3,600 \mathrm{~cm}^{-1}, \mathrm{C}=\mathrm{O}$ at $1,660 \mathrm{~cm}^{-1}$, $\mathrm{C}-\mathrm{O}$ at $1,074 \mathrm{~cm}^{-1}$, and $\mathrm{C}-\mathrm{H}\left(s p^{3}\right)$ at $2,800-3,000 \mathrm{~cm}^{-1}$ as well as bending features of $\mathrm{NH}_{2}$ at $1,597 \mathrm{~cm}^{-1}$ and $\mathrm{C}-\mathrm{N}$ at $1,374 \mathrm{~cm}^{-1}$, as shown in Figure 2A. The vibrational features of EGF rising from amide I, amide II, and amide III at 1,653, 1,542, and 1,402 $\mathrm{cm}^{-1}$, respectively, are shown in Figure 2B. The spectrum of chitosan-EGF conjugate displays the FT-IR profile of chitosan with some red-shifts and additional bands at 1,563 and $1,423 \mathrm{~cm}^{-1}$ rising from vibrations of amide (Figure 2C). Vibrations of amides indicate the conjugation of chitosan and EGF. TPP can be recognized by FT-IR

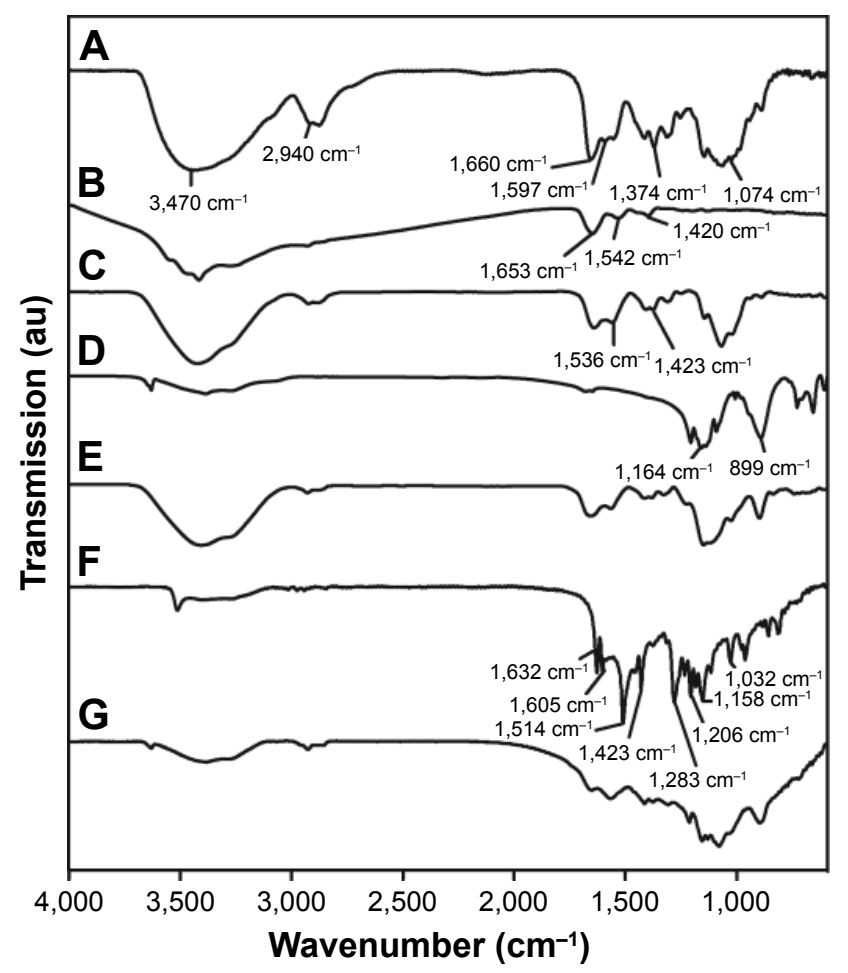

Figure 2 IR spectra of CENP and its components. (A) Chitosan, (B) EGF, (C) EGFconjugated chitosan, (D) TPP, (E) ENP, (F) curcumin, and (G) CENP.

Abbreviations: CENP, curcumin-encapsulated and EGF-conjugated chitosan/TPP nanoparticles; EGF, epidermal growth factor; ENP, EGF-conjugated chitosan/TPP nanoparticles; IR, infrared; TPP, tripolyphosphate. 
bands at 1,164 and $899 \mathrm{~cm}^{-1}$ for $\mathrm{P}=\mathrm{O}$ and $\mathrm{P}-\mathrm{O}-\mathrm{P}$ stretching, respectively, as illustrated in Figure 2D. After the crosslinking reaction is carried out in TPP and EGF-conjugated chitosan, all bands of EGF, chitosan, and TPP are preserved (Figure 2E), thus confirming the assembly of ENP. Curcumin has abundant vibrational features as shown in Figure 2F. The significant ones include stretching modes of aromatic $\mathrm{O}-\mathrm{H}$ at $\sim 3,400 \mathrm{~cm}^{-1}, \mathrm{C}=\mathrm{O}$ at $1,632 \mathrm{~cm}^{-1}$, aromatic $\mathrm{C}=\mathrm{C}$ at $1,605 \mathrm{~cm}^{-1}$, and aromatic $\mathrm{C}-\mathrm{C}$ at 1,514 and $1,423 \mathrm{~cm}^{-1}$. Other vibrations of curcumin are observed at 1,283 and $1,206 \mathrm{~cm}^{-1}$ for $\mathrm{C}-\mathrm{O}, 1,158 \mathrm{~cm}^{-1}$ for $\mathrm{C}-\mathrm{O}-\mathrm{C}$, and $1,032 \mathrm{~cm}^{-1}$ for $\mathrm{C}-\mathrm{H}$. After the assembly of TPP with curcumin and EGF-conjugated chitosan, vibrational bands representing curcumin, TPP, and EGF-conjugated chitosan are all present in CENP in Figure 2G.

To examine the photoactivity of encapsulated curcumin, we compared the absorption and fluorescence spectra of curcumin and CENP. As shown in Figure S4, the absorption spectra of curcumin and CNP are almost superimposed. The fluorescence of CNP is higher than that of curcumin. The enhanced fluorescence quantum yield can be ascribed to the encapsulation of nanoparticles, as reported previously. ${ }^{24,25}$ This result indicates that encapsulated curcumin has better photoactivity than free curcumin.

\section{Cell viability before and after PDT with various nanoparticles}

After physical and chemical characterization of various nanoparticles, we conducted experiments on cells including MKN45, an EGFR-overexpressing gastric cancer cell, and GES, a non-cancer gastric cell. Cell viability assays were undertaken on both GES and MKN45 cells treated with various nanoparticles.

The viability of cells in the presence of the fabricated NPs before PDT was initiated was used as a measure of the toxicity of nanoparticles. Chitosan and TPP are highly biocompatible and have been applied in regenerative medicine ${ }^{26}$ and drug delivery. ${ }^{27}$ The positive charges of the NPs promote payload delivery to the negatively charged cell surface. Before the illumination, curcumin was weakly toxic to both GES and MKN45 when the concentration of curcumin was higher than $20 \mu \mathrm{M}$, whereas CNP had no dark toxicity (Figure 3A and C). Our data suggest that the toxicity of curcumin at high doses is abolished when encapsulated within NP.

After PDT is activated by illumination, the level of cell viability for both treatments was very similar in both types of cells (Figure 3B and D). This result indicates that curcumin released from CNP functioned as well as free curcumin in PDT.
Subsequently, we compared the PDT effect on MKN45 and GES treated with nanoparticles in the absence of curcumin (NP, ENP, and FNP) and in the presence of curcumin (CNP, CENP, and CFNP). As shown in Figure 3E, in the absence of curcumin, cells survive very well, indicating that nanoparticles as drug carriers are not toxic to the cells. As shown in Figure 3F, treatments with CENP and CFNP cause significant cellular toxicity in MKN45 but not in GES. Both EGF and folate play the role of targeting very well. Comparatively, EGF is more efficient than folate by approximately twofold. As CENP is the most efficient formulation for PDT on MKN45, the dose dependence was tested, as illustrated in Figure $3 \mathrm{G}$ and $\mathrm{H}$. To quantitatively compare the PDT effect of CNP and CENP, the $\mathrm{IC}_{50}$ of CNP and CENP on MKN45 and GES were determined as shown in Figure $3 \mathrm{H}$. The data analysis indicated that the $\mathrm{IC}_{50}$ of CENP on MKN45 was $3.4 \mu \mathrm{M}$, which was more efficient than CNP on MKN45 $\left(\mathrm{IC}_{50}=11.9 \mu \mathrm{M}\right), \mathrm{CNP}$ on $\mathrm{GES}\left(\mathrm{IC}_{50}=13.1 \mu \mathrm{M}\right)$, and CENP on GES $\left(\mathrm{IC}_{50}=12.8 \mu \mathrm{M}\right)$. The $\mathrm{IC}_{50}$ of $\mathrm{CNP}$ is very close to the result of curcumin-PDT tested in liver tumor cells. ${ }^{28}$

Folate receptors are highly expressed in many kinds of tumors. ${ }^{29}$ Some patients with gastric cancer were found to be folate-receptor- $\alpha$ positive, whereas the expression of folate-receptor $\alpha$ was lower than ovarian tumors. ${ }^{30}$ The folate receptor-conjugated complex has been applied in many kinds of tumors, including gastric cancer cell line. ${ }^{31}$ As folate is widely used in targeted therapy of cancers, we prepared CFNP as a comparator reference for our fabricated nanoparticles. In the viability assay, CFNP is a better photosensitizer than CNP ascribed to folate-directed PDT in MKN45. CENP is a lot more effective than CFNP. The superior effect of CENP in comparison to CFNP could be due to different expression levels of EGFR and folate receptors in MKN45. Undoubtedly, our directed PDT undertaken by CENP significantly strengthened the effect of PDT.

\section{Flow cytometry and IL- 10 measurement of CENP-PDT-treated cells}

Apoptosis and necrosis are two major mechanisms of cell death. To distinguish the mechanism of cell death in CENPPDT, we undertook flow cytometry. As illustrated in Figure 4, in MKN45, 8.65\% and $69.4 \%$ of cells belong to early-stage and late-stage apoptosis/necrosis, respectively, whereas $1.12 \%$ of cells die through necrosis. In GES, $1.17 \%$ and $7.98 \%$ of cells belong to early-stage and late-stage apoptosis/ necrosis, and $21.1 \%$ of cells are categorized as necrotic. The distinct pattern of flow cytometry indicates that MKN45 and GES have different responses to CENP. 


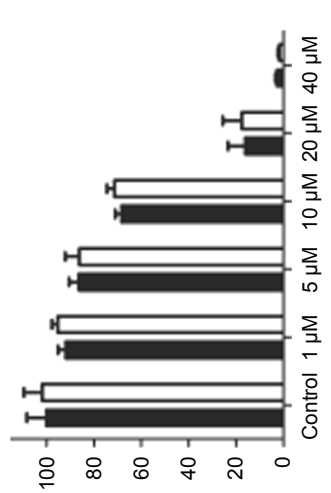

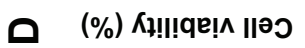

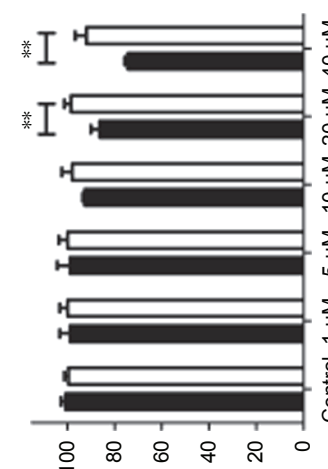

0
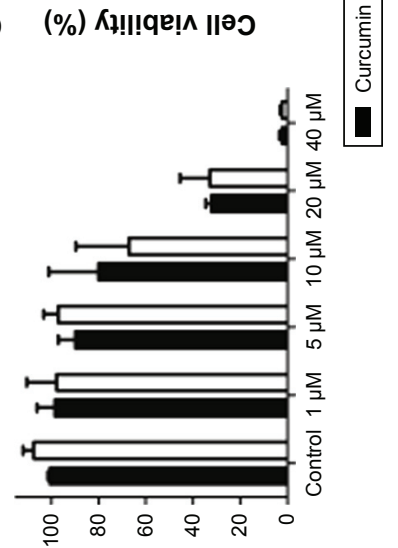

m (\%) Кł!!!qе!^ ||әว

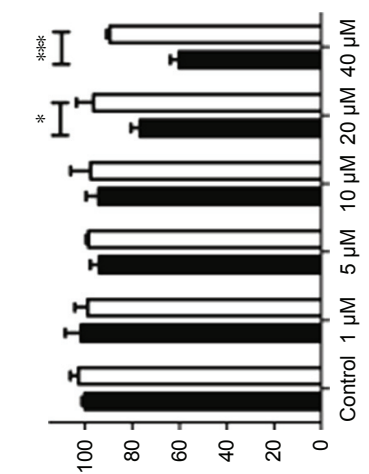

$\varangle \quad(\%)$ К‼!qอ!ฺ ॥әว

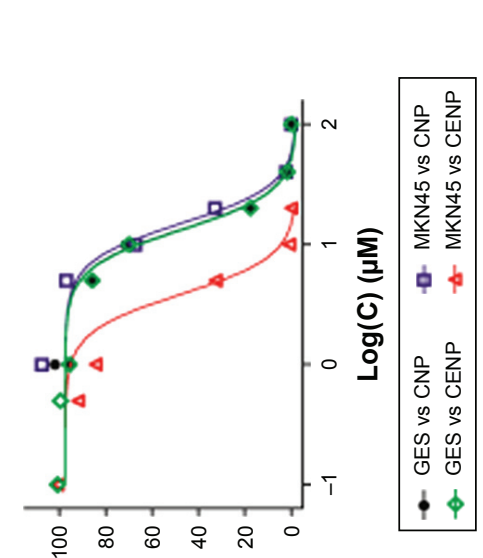

I (\%) К१!!!qए!^ ॥әว

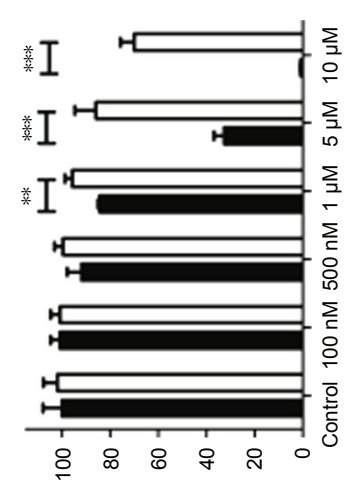

(ง) (\%) К!!!!q!ฺ ||әว

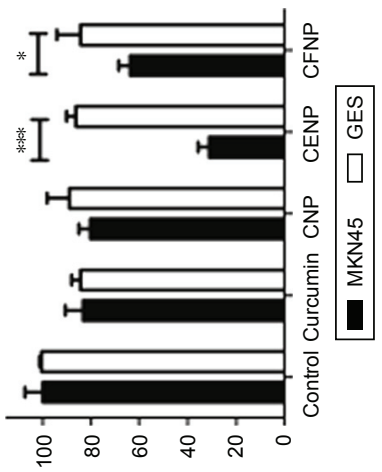

ᄂ (\%) К‼!qе!ฺ ||ә弓

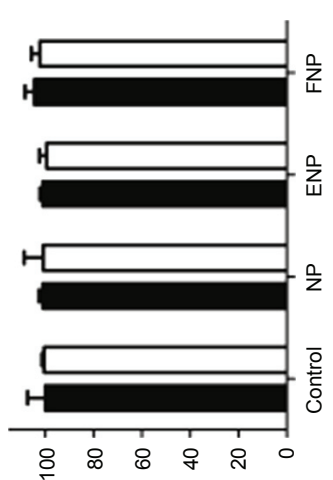

Ш (\%) Кұ!!!qए!^ ||ә弓

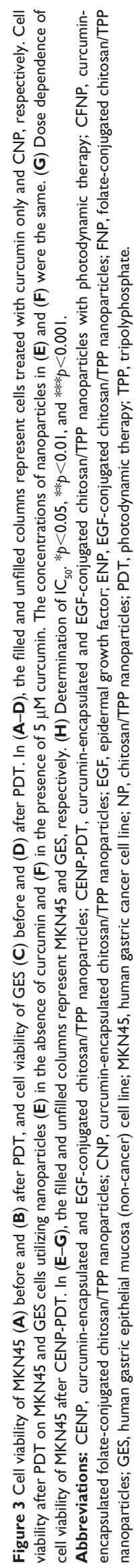



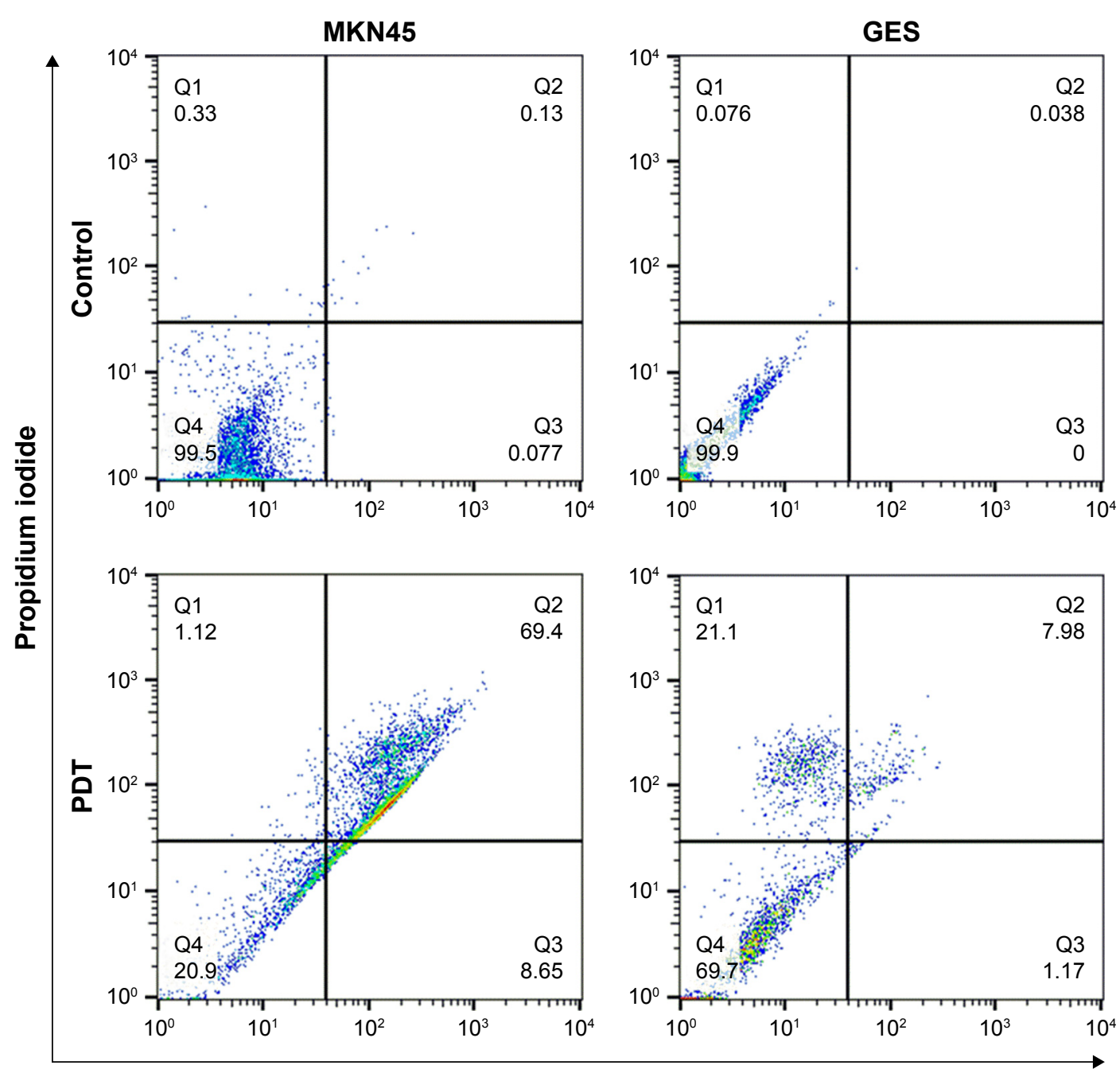

Annexin V-FITC

Figure 4 Apoptosis and necrosis of MKN45 and GES after CENP-PDT detected by flow cytometry with Annexin $\mathrm{V}$ and PI staining.

Abbreviations: CENP-PDT, curcumin-encapsulated and EGF-conjugated chitosan/TPP nanoparticles with photodynamic therapy; EGF, epidermal growth factor; FITC, fluorescein isothiocyanate; GES, human gastric epithelial mucosa (non-cancer) cell line; MKN45, human gastric cancer cell line; PDT, photodynamic therapy; PI, propidium iodide; TPP, tripolyphosphate.

Immune response is a critical issue in cancer therapies. ${ }^{32}$ We tested the immune response of MKN45 to CENP-PDT by quantitation of IL-10 (an anti-inflammatory cytokine). As shown in Figure S5, CENP-PDT did not result in any anti-inflammatory effects.

\section{Localization and uptake of CENP}

After studying the cellular toxicity of PDT, we were interested in the location at which PDT is carried out, especially for the most efficient nanoparticles. Therefore, we examined the location of curcumin in the cells by fluorescence imaging, with DAPI labeling of cell nuclei after PDT utilizing CENP. Curcumin and DAPI emit yellowish green and blue fluorescence, respectively. The fluorescence images of MKN45 and GES in Figure 5B and D indicate that curcumin enters MKN45 considerably but permeates very little in GES. As the fluorescence of curcumin and DAPI is not superimposed, curcumin mainly locates in the cell membrane and partially in cytosol rather than in nuclei. To further confirm the uptake of CENP into the cells, we conducted an uptake assay by quantitation of curcumin in CNP- and CENP-treated MKN45, as shown in Figure 5E. Significantly, curcumin in CENP-treated cells is higher than curcumin in CNP-treated cells by more than twofold. This ratio is consistent with the cell toxicity of CNP and CENP. The curcumin in MKN45 became more concentrated with the progress of treatments. The concentrated curcumin in MKN45 indicates that the abundance of the CENP population in MKN45 could be ascribed to the good cellular uptake and directing effect of CENP. The fabricated nanoparticles, which have positive charges, are capable of interaction with cell membranes carrying negative charges. This ionic 

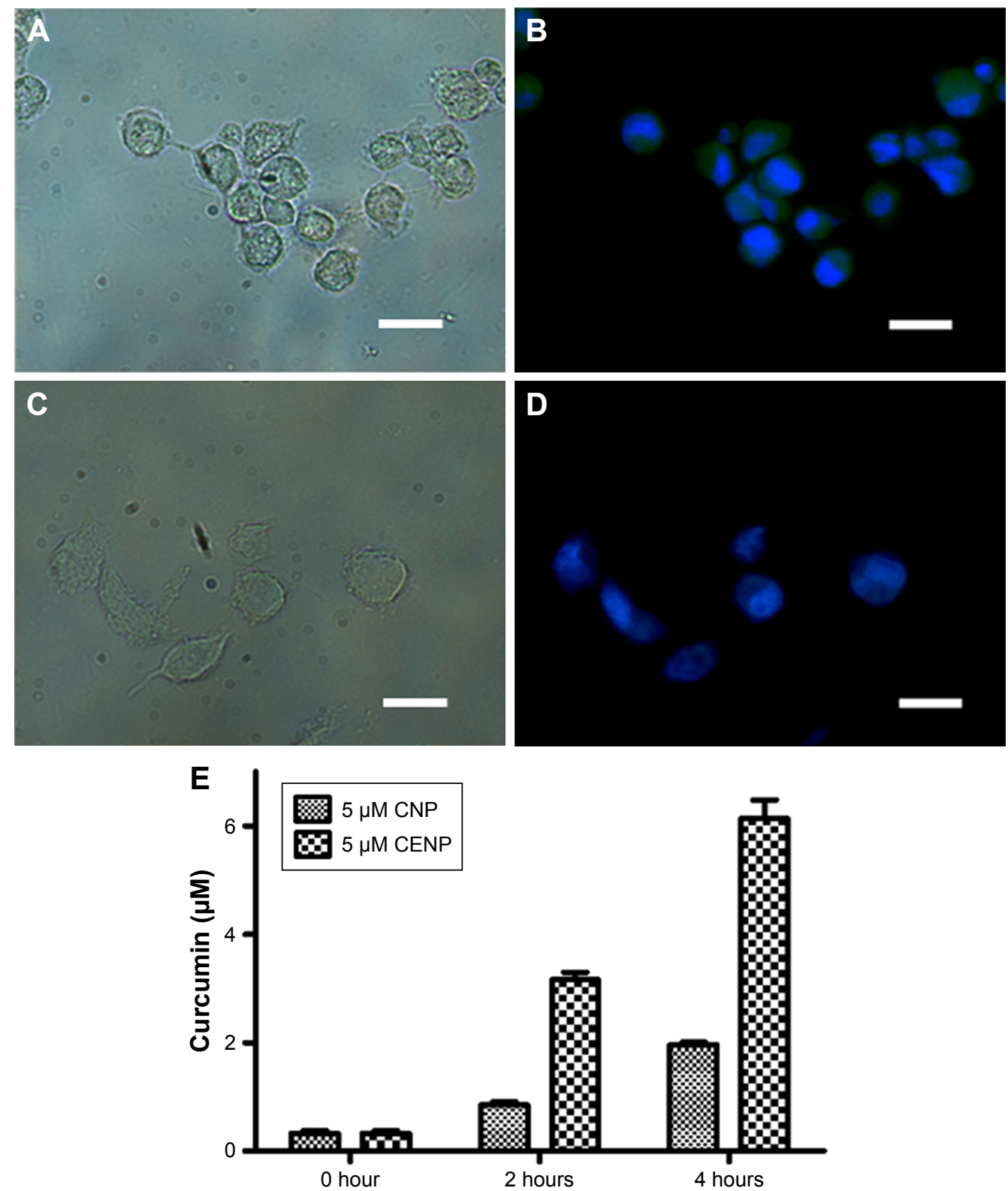

Figure 5 (A-D) Images of CENP-PDT-treated cells. The light image of (A) MKN45 and (C) GES. Superimposition of fluorescence images after DAPI staining on (B) MKN45 and (D) GES. Curcumin has inherent yellowish green fluorescence and DAPI provides blue fluorescence. The scale bar represents $20 \mu \mathrm{m}$. (E) Time course of curcumin quantitation in CNP- and CENP-treated MKN45.

Abbreviations: CENP, curcumin-encapsulated and EGF-conjugated chitosan/TPP nanoparticles; CENP-PDT, curcumin-encapsulated and EGF-conjugated chitosan/TPP nanoparticles with photodynamic therapy; CNP, curcumin-encapsulated chitosan/TPP nanoparticles; DAPI, 4',6-diamidino-2-phenylindole; EGF, epidermal growth factor; GES, human gastric epithelial mucosa (non-cancer) cell line; MKN45, human gastric cancer cell line; PDT, photodynamic therapy;TPP, tripolyphosphate.

interaction can accelerate the recognition of EGF on CENP and EGFR on the cell membranes of MKN45. After this ligand-receptor recognition, CENP can enter the cells through receptor-mediated endocytosis ${ }^{33}$ for subsequent PDT reactions. This post-endocytic EGFR trafficking is special for the recycling to the cell surface. ${ }^{34}$ This recycling promotes the accumulation of liposoluble curcumin in cell membranes. Taking together the results of flow cytometry and localization of CENP, we proposed a possible scenario of CENP-PDT that ROS in the surrounding of GES cell membrane induced necrosis of GES. Differently, ROS populating the cytosol of MKN45 initiate apoptosis.

\section{Analysis of ROS and ' $\mathrm{O}_{2}$ production in PDT}

The production of ROS is the most essential part of PDT. The level of ROS in each nanoparticle treatment is compared in Figure 6A. In the absence of curcumin, ROS was not generated. In the presence of curcumin, the ROS level was the same in all nanoparticle-treated GES cells. In contrast, ROS was 

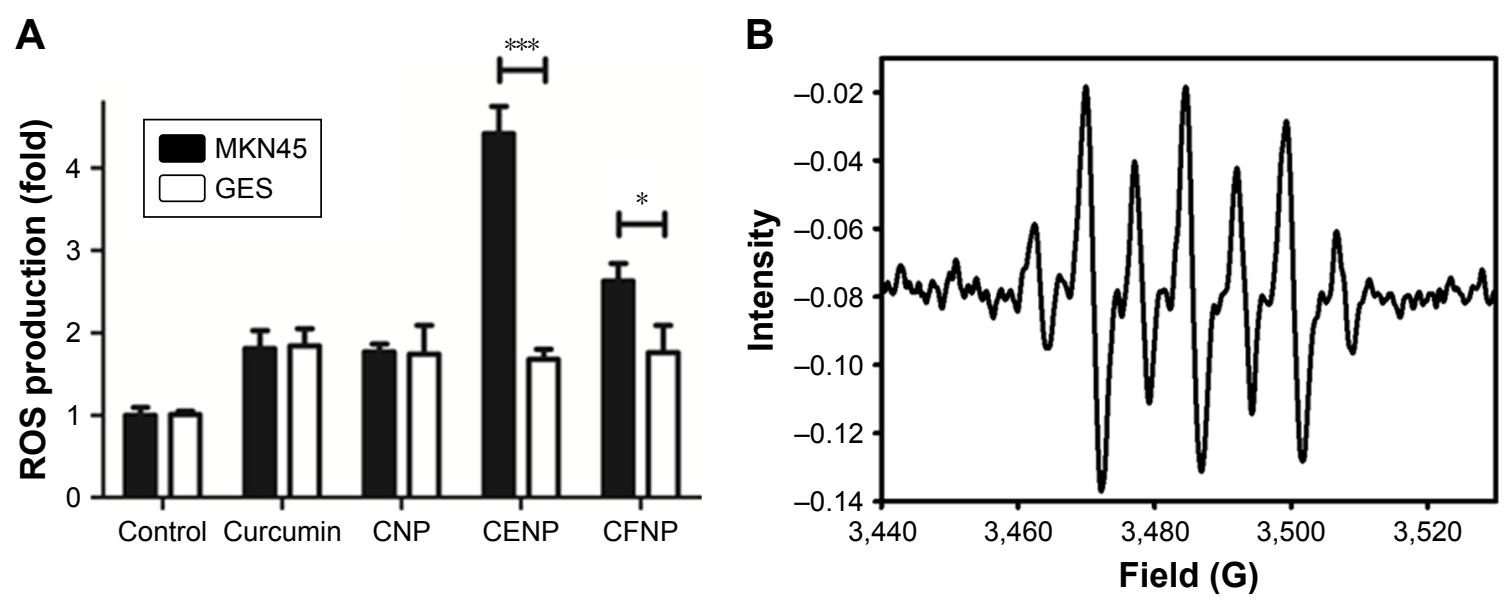

Figure 6 Analysis of (A) ROS in PDT treated with various nanoparticles and (B) ' $\mathrm{O}_{2}$ production determined by an EPR spin-trapping experiment with DMPO. Note: $* p<0.05, * * * p<0.001$.

Abbreviations: ' $\mathrm{O}_{2}$, singlet oxygen; CENP, curcumin-encapsulated and EGF-conjugated chitosan/TPP nanoparticles; CFNP, curcumin-encapsulated folate-conjugated chitosan/TPP nanoparticles; CNP, curcumin-encapsulated chitosan/TPP nanoparticles; DMPO, 5,5-dimethyl-pyrroline N-oxide; EGF, epidermal growth factor; EPR, electron paramagnetic resonance; GES, human gastric epithelial mucosa (non-cancer) cell line; MKN45, human gastric cancer cell line; PDT, photodynamic therapy; ROS, reactive oxygen species; TPP, tripolyphosphate.

productively generated in CENP- and CFNP-treated MKN45. This result indicates that PDT was more effective when the drug carrier targets the cancer cells. Similar to cell viability, CENP was more efficient in ROS generation than CFNP by approximately twofold. This manifestation suggests that cell toxicity was caused by ROS generation during PDT.

ROS generated in PDT include free radicals (type I) and ${ }^{1} \mathrm{O}_{2}$ (type II). Most PDTs are carried out through the type II mechanism. ${ }^{2}$ To examine whether ${ }^{1} \mathrm{O}_{2}$ is generated in our PDT experiments, we conducted an EPR spin trapping experiment employing DMPO on CNP. As shown in Figure 6B, the hyperfine splitting of DMPO can be assigned to coupling of ${ }^{1} \mathrm{O}_{2}$, as reported previously. ${ }^{35,36}$ This result indicates that PDT utilizing curcumin or curcumin-containing nanoparticles was carried out in the type II pathway. The most critical issue of type II PDT is the enrichment of $\mathrm{O}_{2}$ near the photosensitizer. ${ }^{37}$ As hypoxia commonly presents in cancer tissues, ${ }^{38}$ the therapeutic effect of type II PDT is largely weakened. Therefore, abundant studies have focused on the issue of hypoxia, such as the use of hypoxia-activated drugs, ${ }^{39}$ anti-angiogenic drugs, ${ }^{40}$ and inhibitors of the hypoxia-inducer factor. ${ }^{41}$ Some approaches on oxygen generation and carriers have been demonstrated. ${ }^{42}$ With regard to the approach to solving the problem of hypoxia in PDT, it is predicable that the targeted PDT can potentially be a very effective cancer therapy without considerable side effects.

\section{Conclusion}

In summary, we undertook a targeted cancer therapy on EGFR-overexpressing tumor cells through PDT by utilizing EGF conjugation and curcumin encapsulation with NP. Our results show that CENP is taken up by EGFR-overexpressing cells and that curcumin is released from the CENP in the cell membrane and cytosol. The fabricated NP are highly stable under aqueous conditions and enhanced the effect of liposoluble curcumin as a photosensitizer. In this work, CENP-PDT is carried out through type II PDT generating ${ }^{1} \mathrm{O}_{2}$. The same approach can be applied to other PDTs with different photosensitizers, especially for improvement of the transparency of irradiation. Short penetration of visible light is an important issue of PDT, as the excitation wavelength of curcumin for PDT is relatively short. Thus, the application of CENP will be limited to superficial tumors. To overcome this limitation, further development of photosensitizers suitable for targeted therapy of deep tumors is much required. In addition, the application of curcumin can be expanded further by the encapsulation and release of the NP.

\section{Acknowledgments}

The authors are grateful to the Ministry of Science and Technology for financial support (MOST 106-2113-M-194-009). The authors thank Professor Cheng-Liang Huang of the National Chia-Yi University for technical support in TEM imaging and Professor Peter PY Chen of the National Chung Hsing University for technical support in EPR measurements. The authors also thank Dr Raymond Chung for editing the manuscript and Professor Michael WY Chan for providing the GES cell line.

\section{Disclosure}

The authors report no conflicts of interest in this work. 


\section{References}

1. Agostinis P, Berg K, Cengel KA, et al. Photodynamic therapy of cancer: an update. CA Cancer J Clin. 2011;61(4):250-281.

2. Dolmans DE, Fukumura D, Jain RK. Photodynamic therapy for cancer. Nat Rev Cancer. 2003;3(5):380-387.

3. Chatterjee A, Oh DJ, Kim KM, Youk KS, Ahn KH. Selective colorimetric sensing of geometrical isomers of dicarboxylates in water by using functionalized gold nanoparticles. Chem Asian J. 2008;3(11): 1962-1967.

4. Hatcher H, Planalp R, Cho J, Torti FM, Torti SV. Curcumin: from ancient medicine to current clinical trials. Cell Mol Life Sci. 2008; 65(11):1631-1652.

5. Maheshwari RK, Singh AK, Gaddipati J, Srimal RC. Multiple biological activities of curcumin: a short review. Life Sci. 2006;78(18): 2081-2087.

6. Bar-Sela G, Epelbaum R, Schaffer M. Curcumin as an anti-cancer agent: review of the gap between basic and clinical applications. Curr Med Chem. 2010;17(3):190-197.

7. Basnet P, Skalko-Basnet N. Curcumin: an anti-inflammatory molecule from a curry spice on the path to cancer treatment. Molecules. 2011; 16(6):4567-4598.

8. Hamaguchi T, Ono K, Yamada M. REVIEW: curcumin and Alzheimer's disease. CNS Neurosci Ther. 2010;16(5):285-297.

9. Federico A, Cardaioli E, Da Pozzo P, Formichi P, Gallus GN, Radi E. Mitochondria, oxidative stress and neurodegeneration. J Neurol Sci. 2012;322(1-2):254-262.

10. Ahmad B, Lapidus LJ. Curcumin prevents aggregation in $\alpha$-synuclein by increasing reconfiguration rate. J Biol Chem. 2012;287(12): 9193-9199.

11. Lin CF, Yu KH, Jheng CP, Chung R, Lee CI. Curcumin reduces amyloid fibrillation of prion protein and decreases reactive oxidative stress. Pathogens. 2013;2(3):506-519.

12. Koon H, Leung AW, Yue KK, Mak NK. Photodynamic effect of curcumin on NPC/CNE2 cells. J Environ Pathol Toxicol Oncol. 2006; 25(1-2):205-215.

13. Yallapu MM, Jaggi M, Chauhan SC. Curcumin nanoformulations: a future nanomedicine for cancer. Drug Discov Today. 2012;17(1-2): 71-80.

14. Wanninger S, Lorenz V, Subhan A, Edelmann FT. Metal complexes of curcumin - synthetic strategies, structures and medicinal applications Chem Soc Rev. 2015;44(15):4986-5002.

15. Khor E, Lim LY. Implantable applications of chitin and chitosan. Biomaterials. 2003;24(13):2339-2349.

16. Lee ST, Mi FL, Shen YJ, Shyu SS. Equilibrium and kinetic studies of copper(II) ion uptake by chitosan-tripolyphosphate chelating resin. Polymer. 2001;42(5):1879-1892.

17. Pati F, Adhikari B, Dhara S. Development of chitosan-tripolyphosphate fibers through $\mathrm{pH}$ dependent ionotropic gelation. Carbohydr Res. 2011; 346(16):2582-2588.

18. Gan Q, Wang T, Cochrane C, McCarron P. Modulation of surface charge, particle size and morphological properties of chitosan-TPP nanoparticles intended for gene delivery. Colloids Surf B Biointerfaces. 2005;44(2-3):65-73.

19. Yan L, Rosen N, Arteaga C. Targeted cancer therapies. Chin J Cancer. 2011;30(1):1-4.

20. Gerber DE. Targeted therapies: a new generation of cancer treatments. Am Fam Physician. 2008;77(3):311-319.

21. Wu CS, Wei KL, Chou JL, et al. Aberrant JAK/STAT signaling suppresses TFF1 and TFF2 through epigenetic silencing of GATA6 in gastric cancer. Int J Mol Sci. 2016;17(9). pii: E1467.

22. Villalobos-Hernández JR, Müller-Goymann CC. Novel nanoparticulate carrier system based on carnauba wax and decyl oleate for the dispersion of inorganic sunscreens in aqueous media. Eur J Pharm Biopharm. 2005;60(1):113-122.
23. Hu B, Pan C, Sun Y, Hou Z, Ye H, Zeng X. Optimization of fabrication parameters to produce chitosan-tripolyphosphate nanoparticles for delivery of tea catechins. J Agric Food Chem. 2008;56(16):7451-7458.

24. Albota M, Beljonne D, Brédas JL, et al. Design of organic molecules with large two-photon absorption cross sections. Science. 1998; 281(5383):1653-1656.

25. Larson DR, Ow H, Vishwasrao HD, Heikal AA, Wiesner U, Webb WW. Silica nanoparticle architecture determines radiative properties of encapsulated fluorophores. Chem Mater. 2008;20(8):2677-2684.

26. Muzzarelli RA, El Mehtedi M, Bottegoni C, Aquili A, Gigante A. Genipin-crosslinked chitosan gels and scaffolds for tissue engineering and regeneration of cartilage and bone. Mar Drugs. 2015;13(12): 7314-7338.

27. Fakhari A, Anand Subramony J. Engineered in-situ depot-forming hydrogels for intratumoral drug delivery. J Control Release. 2015; 220(Pt A):465-475.

28. Ellerkamp V, Bortel N, Schmid E, Kirchner B, Armeanu-Ebinger S, Fuchs J. Photodynamic therapy potentiates the effects of curcumin on pediatric epithelial liver tumor cells. Anticancer Res. 2016;36(7): 3363-3372.

29. Parker N, Turk MJ, Westrick E, Lewis JD, Low PS, Leamon CP. Folate receptor expression in carcinomas and normal tissues determined by a quantitative radioligand binding assay. Anal Biochem. 2005;338(2): 284-293.

30. Sasaki Y, Miwa K, Yamashita K, et al. A phase I study of farletuzumab, a humanized anti-folate receptor $\alpha$ monoclonal antibody, in patients with solid tumors. Invest New Drugs. 2015;33(2):332-340.

31. Luo X, Peng X, Hou J, Wu S, Shen J, Wang L. Folic acid-functionalized polyethylenimine superparamagnetic iron oxide nanoparticles as theranostic agents for magnetic resonance imaging and PD-L1 siRNA delivery for gastric cancer. Int J Nanomedicine. 2017;12:5331-5343.

32. Medler TR, Cotechini T, Coussens LM. Immune response to cancer therapy: mounting an effective antitumor response and mechanisms of resistance. Trends Cancer. 2015;1(1):66-75.

33. Alberts B, Johnson A, Lewis J, Raff M, Roberts K, Walter P. Molecular Biology of the Cell. 4th ed. New York: Garland Science; 2002.

34. Tomas A, Futter CE, Eden ER. EGF receptor trafficking: consequences for signaling and cancer. Trends Cell Biol. 2014;24(1):26-34.

35. Horikoshi S, Wada Y, Watanabe N, Hidaka H, Serpone N. Near-quantitative mineralization of two refractory triazines under hydrothermalsupercritical aqueous conditions assisted by ozone and UV/ozone. New J Chem. 2003;27(8):1216-1223.

36. Bilski P, Reszka K, Bilska M, Chignell CF. Oxidation of the spin trap 5,5-dimethyl-1-pyrroline N-oxide by singlet oxygen in aqueous solution. J Am Chem Soc. 1996;118(6):1330-1338.

37. Gomer CJ, Razum NJ. Acute skin response in albino mice following porphyrin photosensitization under oxic and anoxic conditions. Photochem Photobiol. 1984;40(4):435-439.

38. Gilkes DM, Semenza GL, Wirtz D. Hypoxia and the extracellular matrix: drivers of tumour metastasis. Nat Rev Cancer. 2014;14(6):430-439.

39. Feng L, Cheng L, Dong Z, et al. Theranostic liposomes with hypoxiaactivated prodrug to effectively destruct hypoxic tumors post-photodynamic therapy. ACS Nano. 2017;11(1):927-937.

40. Jung HS, Han J, Shi H, et al. Overcoming the limits of hypoxia in photodynamic therapy: a carbonic anhydrase IX-targeted approach. J Am Chem Soc. 2017;139(22):7595-7602.

41. Xia Y, Choi HK, Lee K. Recent advances in hypoxia-inducible factor (HIF)-1 inhibitors. Eur J Med Chem. 2012;49:24-40.

42. Jahanban-Esfahlan R, de la Guardia M, Ahmadi D, Yousefi B. Modulating tumor hypoxia by nanomedicine for effective cancer therapy. J Cell Physiol. 2018;233(3):2019-2031. 


\section{Supplementary materials}

The physical characterization of chitosan/tripolyphosphate (TPP) nanoparticles composed of various mass ratios of chitosan and TPP by dynamic light scattering. Stability of nanoparticles (NP) evaluated by $\mathrm{D}_{\mathrm{h}}$ and polydispersity index for 2 weeks, stability of NP at different $\mathrm{pH}$ solutions, release of curcumin from curcumin-encapsulated chitosan/TPP nanoparticles (CNP) absorption and fluorescence spectra of curcumin and CNP, time course of curcumin-release from $\mathrm{NP}$, and quantitation of cytokine IL-10 in untreated and $5 \mu \mathrm{M}$-curcumin-encapsulated and epidermal growth factorconjugated chitosan/TPP nanoparticles-treated MKN45.

Table SI Physical characterization of chitosan/TPP nanoparticles composed of various mass ratio (x:y) of chitosan and TPP by DLS

\begin{tabular}{llll}
\hline CxTPPy & $\mathbf{D}_{\mathbf{h}}(\mathbf{n m})$ & PDI & $\begin{array}{c}\text { Zeta potential } \\
(\mathbf{m V})\end{array}$ \\
\hline CITPPI & & $-4.2 \pm 0.6$ \\
C2TPPI & $1,919 \pm 66$ & $0.302 \pm 0.042$ & $2.6 \pm 0.2$ \\
C3TPPI & $1,459 \pm 63$ & $0.713 \pm 0.184$ & $6.7 \pm 1.3$ \\
C4TPPI & $1,025 \pm 231$ & $0.594 \pm 0.376$ & $11.4 \pm 0.8$ \\
C5TPPI & $742 \pm 38$ & $0.268 \pm 0.104$ & $17.3 \pm 3.5$ \\
C6TPPI & $232 \pm 3$ & $0.167 \pm 0.038$ & $18.4 \pm 1.4$ \\
C7TPPI & $414 \pm 10$ & $0.18 \pm 0.05$ & $22.7 \pm 0.4$ \\
C8TPPI & $446 \pm 10$ & $0.308 \pm 0.026$ & $26.3 \pm 0.9$ \\
C9TPPI & $451 \pm 6$ & $0.4 \pm 0.025$ & $28.9 \pm 1.3$ \\
CI0TPPI & $347 \pm 5$ & $0.403 \pm 0.033$ & $30.4 \pm 0.5$ \\
\hline
\end{tabular}

Note: CxTPPy; $x: y$ refer to the mass ratio of chitosan and TPP.

Abbreviations: $C$, chitosan; $D_{h}$, hydrodynamic diameter; DLS, dynamic light scattering; PDI, polydispersity index; TPP, tripolyphosphate.

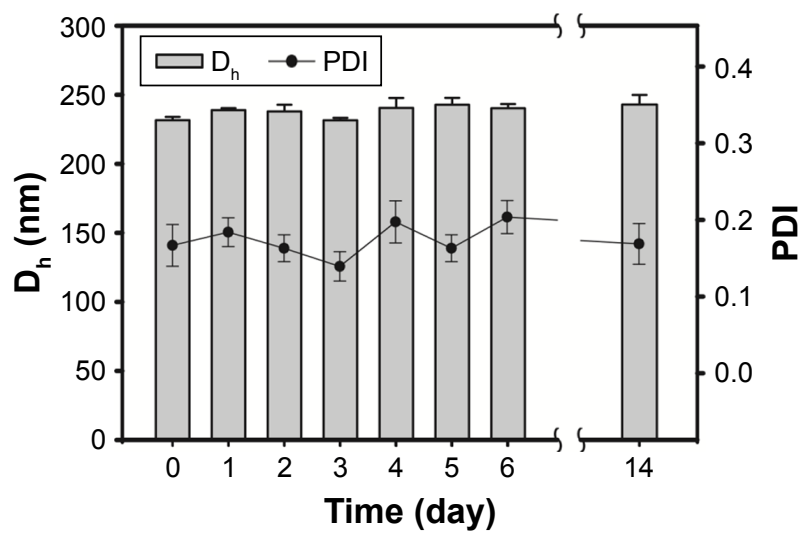

Figure SI Stability of NP at neutral $\mathrm{pH}$ evaluated by $\mathrm{D}_{\mathrm{h}}$ and PDI for 2 weeks.

Abbreviations: $D_{h}$, hydrodynamic diameter; NP, chitosan/TPP nanoparticles; PDI, polydispersity index; TPP, tripolyphosphate.
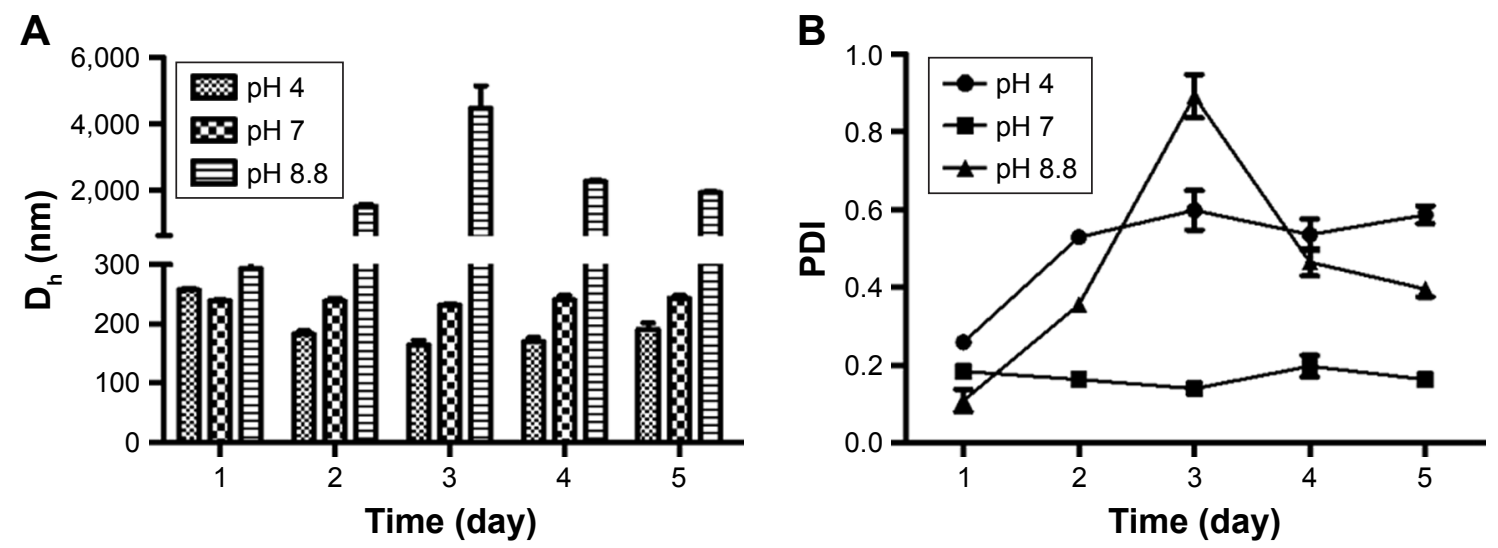

Figure S2 Stability of NP at different $\mathrm{pH}$ solutions evaluated by $(\mathbf{A}) \mathrm{D}_{h}$ and (B) PDI.

Abbreviations: $D_{h}$, hydrodynamic diameter; NP, chitosan/TPP nanoparticles; PDI, polydispersity index; TPP, tripolyphosphate. 


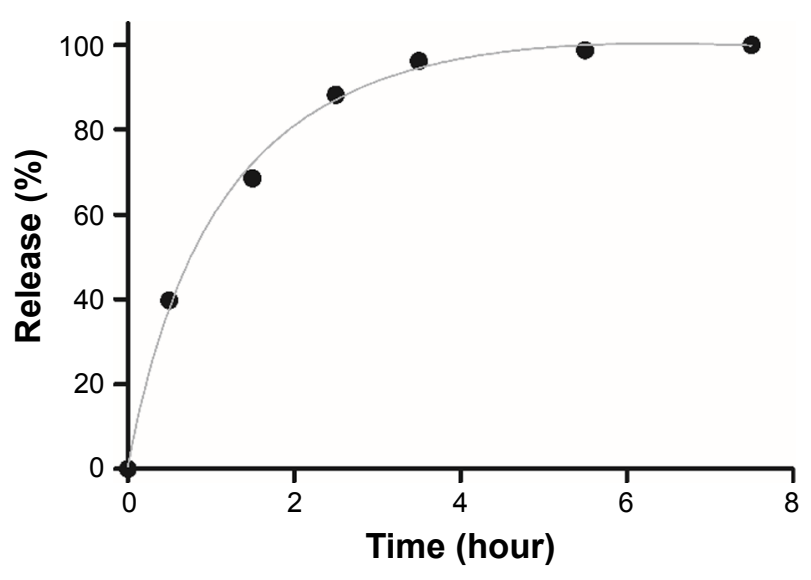

Figure S3 Time course of curcumin release from NP.

Abbreviations: NP, chitosan/TPP nanoparticles; TPP, tripolyphosphate.
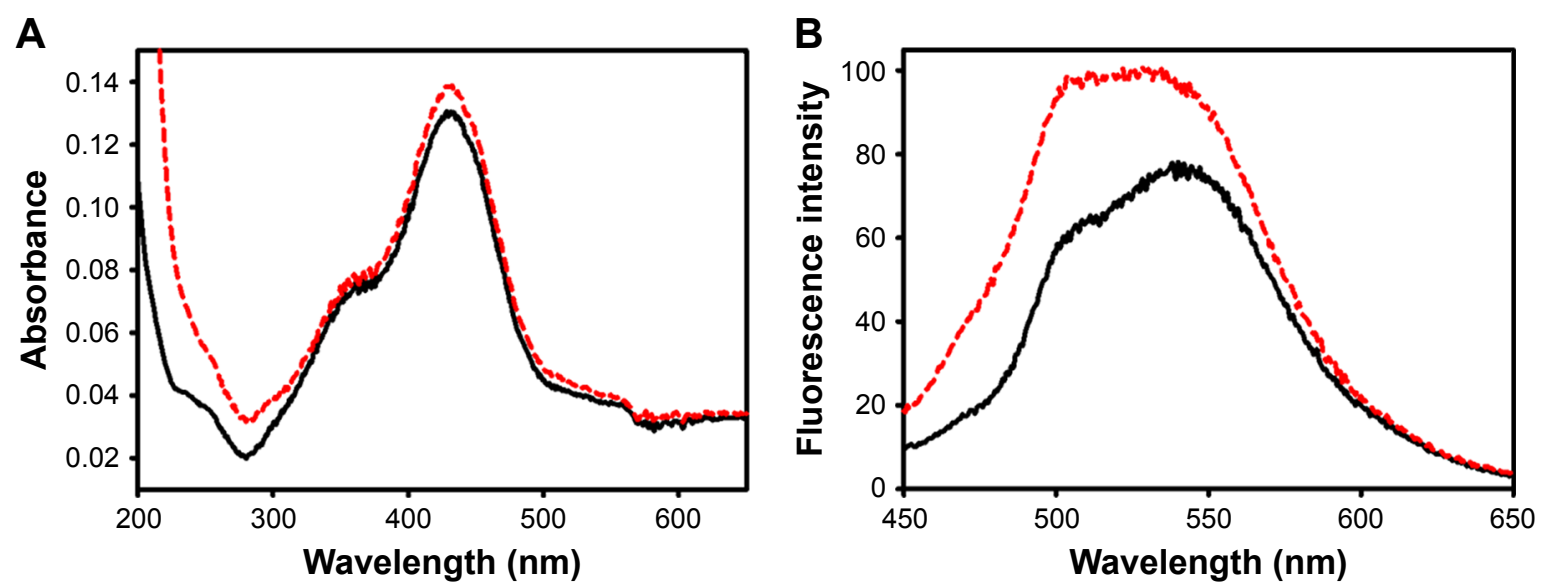

$-5 \mu \mathrm{M}$ curcumin $---5 \mu \mathrm{M}$ CNP

Figure S4 (A) Absorption and (B) fluorescence spectra of curcumin and CNP.

Abbreviations: CNP, curcumin-encapsulated chitosan/TPP nanoparticles; TPP, tripolyphosphate.

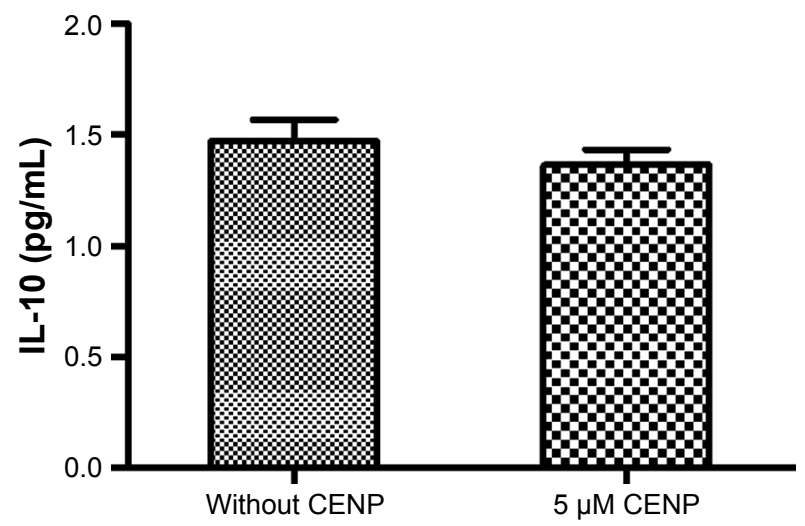

Figure S5 Quantitation of cytokine IL-10 in untreated and $5 \mu$ M-CENP-treated MKN45.

Abbreviations: CENP, curcumin-encapsulated and EGF-conjugated chitosan/TPP nanoparticles; EGF, epidermal growth factor; IL-I0, interleukin I0; MKN45, human gastric cancer cell line; TPP, tripolyphosphate. 


\section{Publish your work in this journal}

The International Journal of Nanomedicine is an international, peerreviewed journal focusing on the application of nanotechnology in diagnostics, therapeutics, and drug delivery systems throughout the biomedical field. This journal is indexed on PubMed Central, MedLine, CAS, SciSearch $\AA$, Current Contents $\AA /$ Clinical Medicine,

Journal Citation Reports/Science Edition, EMBase, Scopus and the Elsevier Bibliographic databases. The manuscript management system is completely online and includes a very quick and fair peer-review system, which is all easy to use. Visit http://www.dovepress.com/ testimonials.php to read real quotes from published authors.

Submit your manuscript here: http://www.dovepress.com/international-journal-of-nanomedicine-journal 